\title{
(อ) OPEN ACCESS \\ Serious games, a game changer in teaching neonatal resuscitation? A review
}

\author{
Simran K Ghoman, ${ }^{1,2}$ Siddhi D Patel, ${ }^{1,3}$ Maria Cutumisu, ${ }^{1,4,5}$ Patrick von Hauff, ${ }^{1,6}$ \\ Thomas Jeffery, ${ }^{1,6}$ Matthew R G Brown, ${ }^{1,5}$ Georg M Schmölzer (1) ${ }^{1,2}$
}

\begin{abstract}
- Additional material is published online only. To view please visit the journal online (http://dx.doi.org/10.1136/ archdischild-2019-317011).

${ }^{1}$ Centre for the Studies of Asphyxia and Resuscitation, Neonatal Research Unit, Royal Alexandra Hospital, Edmonton, Alberta, Canada

2Department of Pediatrics, Faculty of Medicine and Dentistry, University of Alberta, Edmonoton, Alberta, Canada ${ }^{3}$ Faculty of Science, University of Alberta, Edmonoton, Alberta, Canada

${ }^{4}$ Centre for Research in Applied Measurement and Evaluation, University of Alberta, Edmonton, Alberta, Canada ${ }^{5}$ Department of Computing Science, University of Alberta, Edmonton, Alberta, Canada ${ }^{6}$ Academic Technology, Faculty of Medicine and Dentistry, University of Alberta, Edmonton, Alberta, Canada
\end{abstract}

\section{Correspondence to}

Dr Georg M Schmölzer, Centre for the Studies of Asphyxia and Resuscitation, Neonatal Research Unit, Royal Alexandra Hospital, Edmonton, Alberta T5H 3V9, Canada;

georg.schmoelzer@me.com

Received 11 February 2019 Revised 22 May 2019 Accepted 31 May 2019

Published Online First 29 June 2019
ABSTRACT

Background Neonatal healthcare professionals require frequent simulation-based education (SBE) to improve their cognitive, psychomotor and communication skills during neonatal resuscitation. However, current SBE approaches are resource-intensive and not routinely offered in all healthcare facilities. Serious games (board and computer based) may be effective and more accessible alternatives.

Objective To review the current literature about serious games, and how these games might improve knowledge retention and skills in neonatal healthcare professionals.

Method Literature searches of PubMed, Google Scholar, Cochrane Central Register of Controlled Trials, CINAHL, Web of Science and EMBASE databases were performed to identify studies examining serious games in neonatology. All games, such as board games, tabletop games, video games, screen-based simulators, tabletop simulators and virtual reality games were included. Results Twelve serious games were included in this review (four board games, five video games and three virtual reality games). Overall, knowledge improvement was reported for the RETAIN (REsuscitationTrAINing for healthcare professionals) board game (10\% increase in knowledge retention) and The Neonatology Game (4.15 points higher test score compared with control). Serious games are increasingly incorporated into Nursing and Medical School Curriculums to reinforce theoretical and practical learning.

Conclusions Serious games have the potential to improve healthcare professionals' knowledge, skills and adherence to the resuscitation algorithm and could enhance access to SBE in resource-intensive and resource-limited areas. Future research should examine important clinical outcomes in newborn infants.

\section{INTRODUCTION}

Neonatal resuscitation is a highly stressful medical emergency requiring cognitive, psychomotor and communication skills to support making decisions quickly by correctly identifying problems, analysing complex scenarios and generating solutions under elevated time pressure. ${ }^{1}$ This stressful situation can result in distraction, decision-making deficiencies ${ }^{2} 3$ or impaired working memory, ${ }^{4}$ causing medical errors or deviations from the resuscitation algorithm, even in experienced healthcare professionals (HCPs). ${ }^{5}$ Deficiencies in non-technical skills (eg, working memory, decision-making or teamwork) rather than technical skills were the reasons for the majority of fatal errors and poor patient outcomes. ${ }^{6-8}$ Therefore, neonatal resuscitation guidelines recommend

\section{What is already known on this topic?}

- Neonatal healthcare professionals require frequent simulation-based education to improve cognitive, psychomotor and communication skills during resuscitation.

- Alternative simulation-based medical education approaches are required that are equally effective, more accessible and less resource-intensive.

\section{What this study adds?}

- Serious games are potential alternatives to supplement traditional simulation-based education for neonatal resuscitation training.

- Serious games can improve working memory, decision-making and teamwork performance.

- Serious games are increasingly incorporated into Nursing and Medical School Curriculums to reinforce theoretical and practical learning.

simulation-based education (SBE) for HCP to improve working memory, decision-making and teamwork performance. ${ }^{9-12}$

While current SBE programmes such as the Neonatal Resuscitation Program (NRP) have reduced neonatal morbidity and mortality, deficiencies in non-technical skills remain common. ${ }^{13}$ The current SBE approach requires specialised equipment, manikins and instructors trained in simulation education. ${ }^{14}$ Consequently, the current SBE approach is time intensive and cost intensive and therefore not routinely offered in many healthcare facilities. ${ }^{15}$ Also, frequent refresher training sessions are necessary for skill retention, which are cost-prohibitive. ${ }^{14} 16$ Therefore, alternative SBE approaches are needed to improve working memory, decision-making skills and teamwork performance of HCPs. Serious games (eg, board or computer games) fit this description by using active, experiential or problem-based learning to motivate learners to develop these skills. ${ }^{17}$ Game-based learning provides a learning context to construct higher-level knowledge while navigating challenging and iterative scenarios. ${ }^{18}$ Furthermore, serious games have the potential to reduce error rates and are available at low costs. ${ }^{1920}$ Indeed, healthcare areas including surgery, ${ }^{2021}$ emergency medicine ${ }^{22} 23$ and anaesthesiology ${ }^{24}$ have introduced serious games as SBE and reported improved decision-making skills 


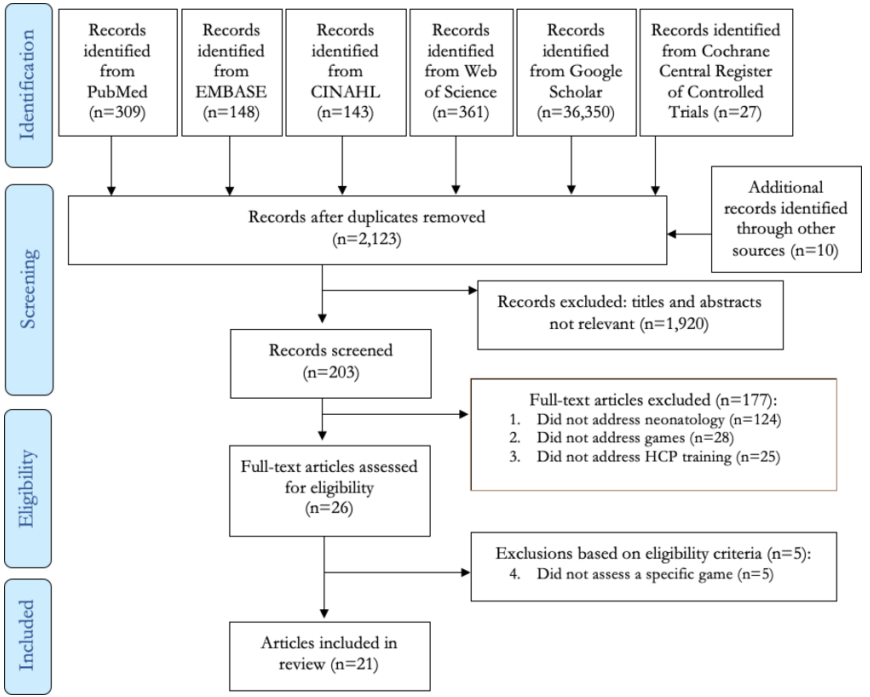

Figure 1 Search strategy for systematic literature review following PRISMA guidelines (last searched 16 May 2019). HCP, healthcare professional; PRISMA, Preferred Reporting Items for Systematic Reviews and Meta-Analyses.

in their learners. However, evidence about the use of serious games in neonatology is lacking. Therefore, we aimed to review the literature about the application of serious games in improving knowledge retention, working memory, decision-making and teamwork performance in neonatal learners.

\section{METHODS}

PubMed, Google Scholar, Cochrane Central Register of Controlled Trials, CINAHL, Web of Science and EMBASE databases were searched from database inception to 21 May 2019 to identify studies examining serious games in neonatology. The search terms included "neonatal", "delivery room", "infant", "baby", "neonatal resuscitation", "serious game”, “computer game”, "board game”, "video game", "virtual reality", "screen-based simulation" and "table-top simulation". No language restrictions were applied. Additionally, the reference lists of retrieved articles were manually screened and studies were selected based on their title, abstract and method, if they addressed neonatology and serious games (online supplementary appendix 1; figure 1). All games including board games, tabletop games, video games, web games, screen-based simulators, tabletop simulators, virtual reality (VR) games and artificial intelligence games were included. Simulation games were included, although distinct from strategic games, as they also fulfil the characteristics of serious games (ie, engaging experience with a challenging goal teaching relevant knowledge and skills). ${ }^{17}$

\section{RESULTS}

A total of 12 games (four board games, five video games and three VR games, as indicated in tables 1 and 2) were identified using our search strategy (figure 1). Articles were excluded if the games were used for reasons other than teaching HCPs' neonatology (eg, parental teaching).

\section{The NRP approach}

\section{NRP eSim}

The eSim (Laerdal Medical, Stavanger, Norway, and American Academy of Pediatrics, Itasca, Illinois, USA) was added to the 2015 NRP provider curriculum to allow for more frequent simulation training. ${ }^{2526}$ The eSim (figure 2) is a digital neonatal resuscitation simulator, which must be completed prior attending the in-class portion of the NRP provider course. ${ }^{25} 26$ Learners complete four different neonatal resuscitation scenarios using interventions and equipment, guided by visual changes in the baby's heart rate, oxygen saturation, breathing, colour and tone. Performance is scored based on adherence to the NRP algorithm. Learners receive a postresuscitation debrief, a timestamped list of their actions categorised as 'correct' or 'needs improvement' and a final score evaluating their performance. A recently completed randomised trial of 255 NRP providers reported that HCPs randomised to pre-NRP course preparation of eSim +NRP textbook performed several steps of the NRP algorithm more correctly compared with HCPs in the textbook-only group (ie, initial steps, mask adjustment, reposition airway). ${ }^{27}$ However, there was no difference in time needed to perform key NRP steps (ie, time to start positive-pressure ventilation (PPV), chest compressions). ${ }^{27}$

\section{Board games}

RETAIN board game

The RETAIN (Resuscitation TrAINing for Healthcare Professionals) board game (RETAIN Labs Medical, Edmonton, Alberta, Canada) is a tabletop serious board game simulator developed to train interdisciplinary HCPs' knowledge, communication and teamwork skills during neonatal resuscitation. During the game, learners are presented with a series of evidence-based scenarios from real-life delivery room resuscitations at the Royal Alexandra Hospital, Edmonton, Alberta, Canada, and perform interventions using equipments, supplies, action and debrief cards, along with adjustable monitors (figure 3 ). The game can be played individually or with up to four learners as an interdisciplinary team (eg, nurse practitioner or respiratory therapist) ${ }^{28}$ Cutumisu et al reported that the board game improved knowledge retention about the NRP algorithm in 30 experienced neonatal HCPs. ${ }^{28}$ Overall, a $12 \%$ increase in knowledge retention was observed between the pre-test and post-test, with the most significant improvement in temperature management. ${ }^{28}$ This suggests the board game might be a low-cost solution to improve knowledge retention. However, further studies are needed to confirm these observations.

\section{The Neonatology Game}

The Neonatology Game (University of Glasgow, Glasgow, UK) is a trivia-based serious board game developed to teach neonatal curriculum to undergraduate medical students. During the game, learners answer general questions about neonatology using summary cards with detailed information about various neonatal conditions in case learners struggle to answer questions. The game is played in teams of up to four learners. ${ }^{29}$ Swiderska et al cluster randomised 67 medical students to play The Neonatology Game combined with the teaching curriculum compared with the teaching curriculum alone. ${ }^{29}$ Overall, students randomised to the board game had a mean post-test score of 4.2 points higher compared with the control group (post-test score of 64.7 vs 60.5$).{ }^{29}$ Students described the game as a positive, useful, fun and interesting learning methodology. ${ }^{29}$ However, there was no pre-test for baseline comparison, therefore results should be interpreted with caution.

\section{Neonatal Emergency Trivia Game}

The Neonatal Emergency Trivia Game (Neonatal Education Specialities, Greensboro, North Carolina, USA) is a trivia-based serious board game developed to help HCPs review neonatology concepts in preparation for emergency clinical events. Similar to 


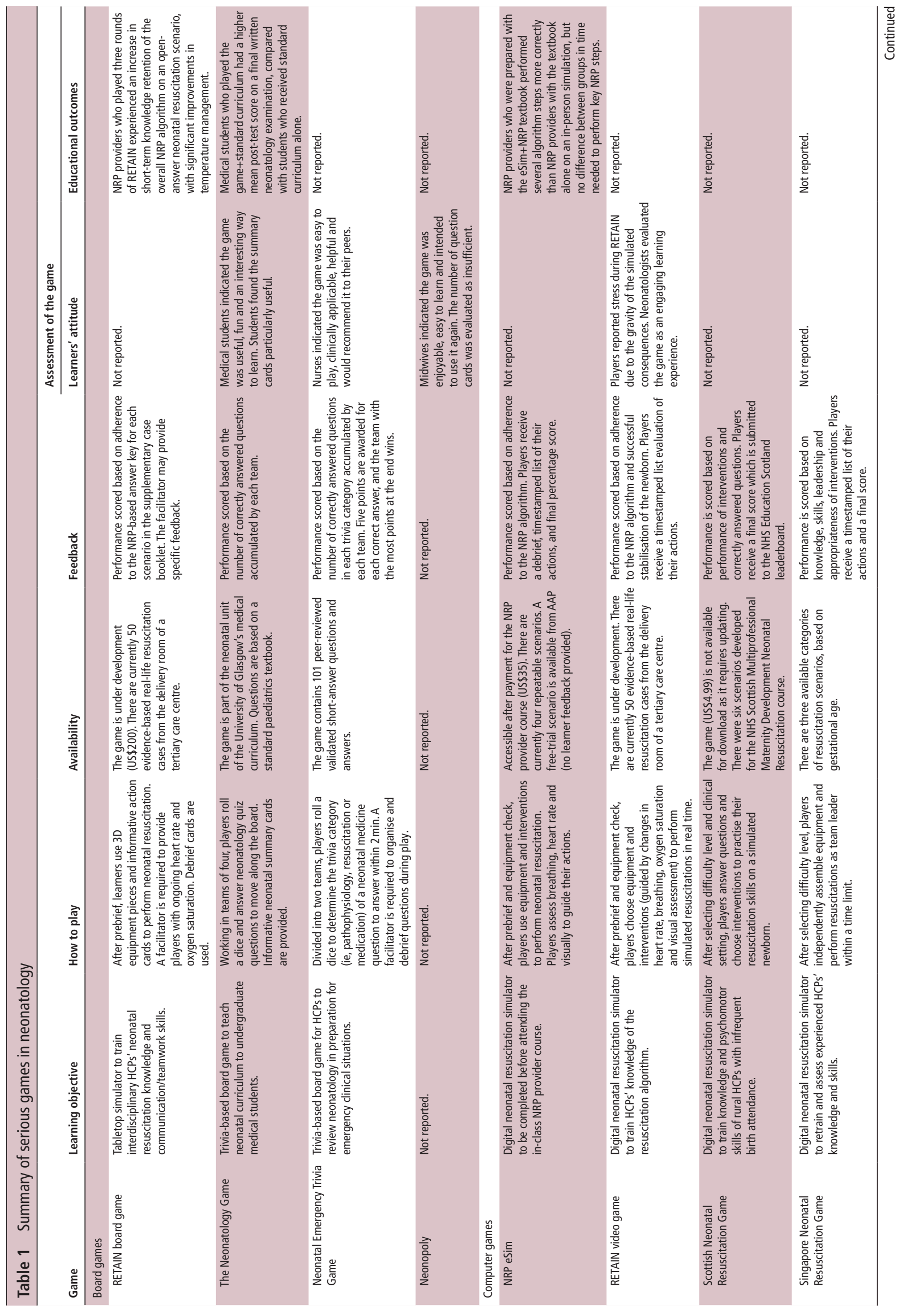


Trivial Pursuit, learners roll dice to determine the trivia category (eg, pathophysiology, resuscitation or medication) and answer 1 of 101 validated peer-reviewed questions about neonatal medicine. ${ }^{30}$ Gordon and Brown reported a strong test-retest reliability (mean $=73$ points, $r=0.76$ ) after administering the same questions twice, 2 weeks apart, to seven neonatal nurses. ${ }^{30}$ Furthermore, 12 clinically experienced nurses evaluated the game with a mean score of 4.8 on a 5 -point Likert scale for clarity and clinical relevance. ${ }^{30}$ No studies have examined any educational or clinical outcomes.

\section{Neonopoly}

The learning objectives, play instructions and availability of Neonopoly (South Africa) were not reported in the literature. However, Swingler conducted a questionnaire with 99 midwives who received the board game to observe learners' usage and attitudes toward the game. ${ }^{31} \mathrm{~A}$ total of $84 \%$ of respondents played the game. From this group, $94 \%$ of participants enjoyed playing, $98 \%$ stated that they will play the game again and $98 \%$ of participants perceived a need for similar games to address other medical areas. ${ }^{31}$ The main limitation of the game included an insufficient number of question cards ${ }^{31}$ and no studies examining any educational or clinical outcomes.

\section{Video games and VR RETAIN}

The RETAIN (REsuscitation TrAINing for healthcare professionals) digital neonatal resuscitation simulator (RETAIN Labs Medical, Edmonton, Alberta, Canada) was designed to help with decision-making skills during neonatal resuscitation (figure 4A, video supplement). ${ }^{32} 33$ In RETAIN, learners take on the role of an HCP attending deliveries. After a brief tutorial, the HCP manages up to 50 evidence-based scenarios of varying difficulty from real-life, delivery room resuscitations at the Royal Alexandra Hospital. ${ }^{132}$ Overall, $50 \mathrm{HCPs}$ reported that the game was stressful because of the seriousness of the object of the game (saving the baby's life). ${ }^{33}$ Furthermore, growth mindset moderated the relationship between participants' task performance in RETAIN and the time since their last refresher NRP course. ${ }^{1}$

\section{Scottish Neonatal Resuscitation Game}

The Neonatal Resuscitation Game (National Health Service (NHS) Education for Scotland, Edinburgh, UK) is a digital neonatal resuscitation simulator developed to teach neonatal resuscitation skills, in particular for rural family physicians with infrequent birth attendance. ${ }^{34}$ The game includes six scenarios, each with various maternal factors, prenatal risks and birth locations. Learners can practise skills such as administering PPV or coordinating chest compressions and submit their final scores to the NHS Education Scotland platform. ${ }^{3435}$ The game is currently incorporated into the NHS Scotland and Scottish Multiprofessional Maternity Development Programme Neonatal Resuscitation Course to reinforce theoretical and practical learning. ${ }^{36}$ However, the game is currently not available for download as it requires updating by the developer. No studies have examined any educational or clinical outcomes.

\section{Singaporean Neonatal Resuscitation Game}

The Singaporean Neonatal Resuscitation Game (Singapore General Hospital, Bukit Merah, Singapore) is a web-based neonatal resuscitation simulator developed to retrain and assess experienced neonatal HCPs. The game allows learners to choose scenarios based on gestational age and level of difficulty. ${ }^{37}$ The 


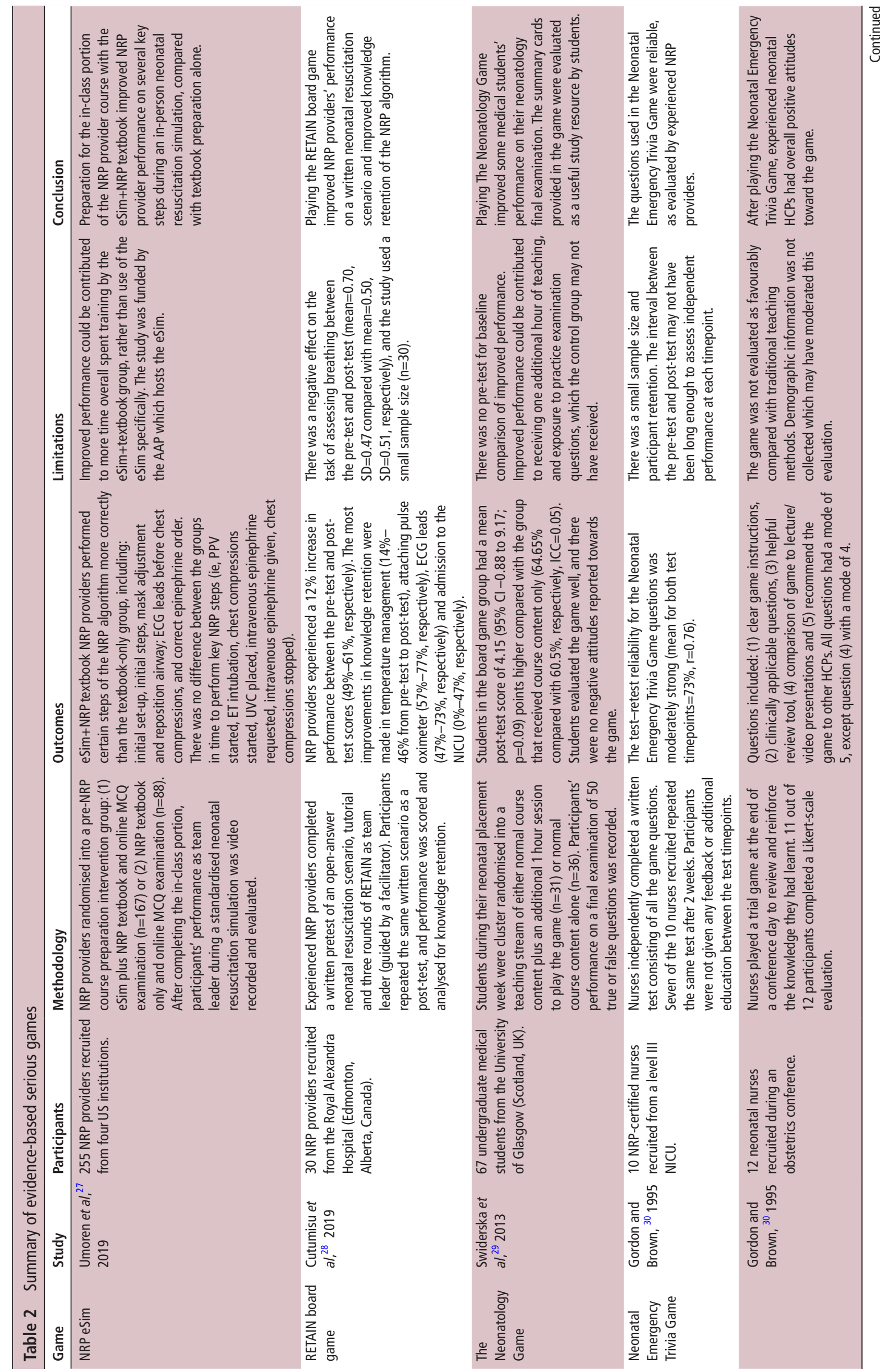




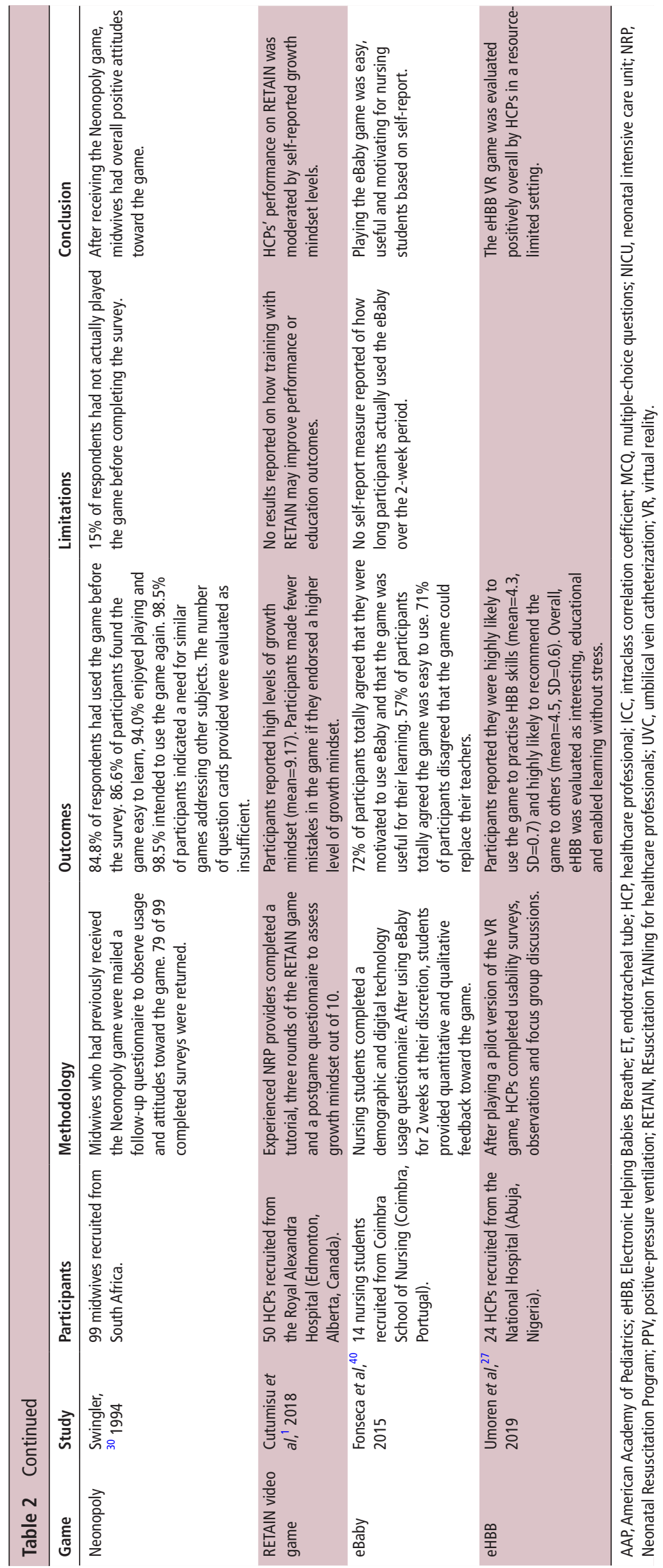




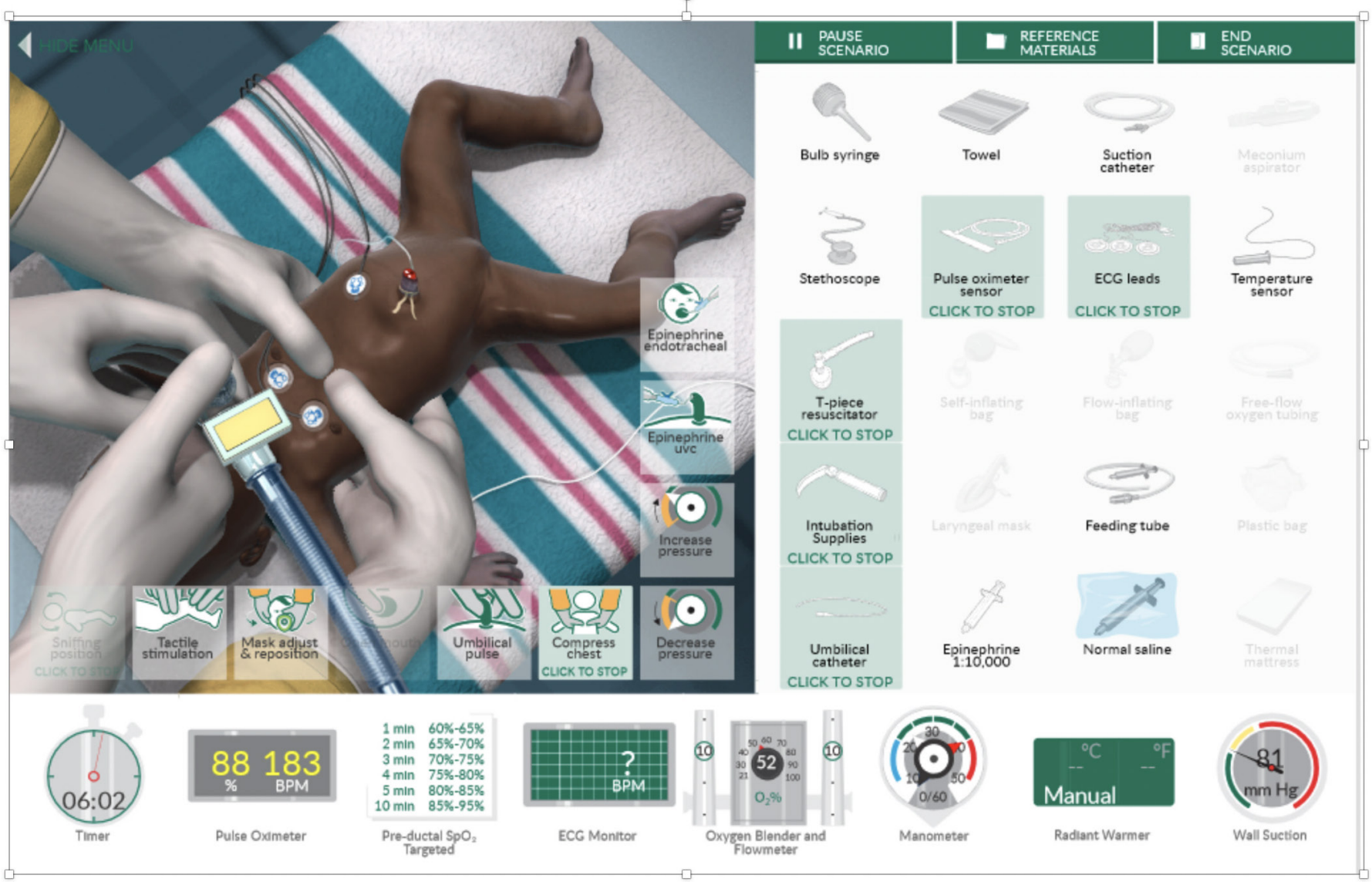

Figure 2 The eSim computer-based virtual neonatal resuscitation simulation from NRP curriculum. BPM, beats per minute; NRP, Neonatal Resuscitation Program.

learner takes on the role of the team leader, while up to three other characters act as assistants. The game provides limited prompts to encourage learners to independently assess the baby and intervene accordingly. At the end of each scenario, learners receive a timestamped summative assessment of their performance. The final score is a combination of the learner's knowledge, technical skills, appropriateness of actions and leadership

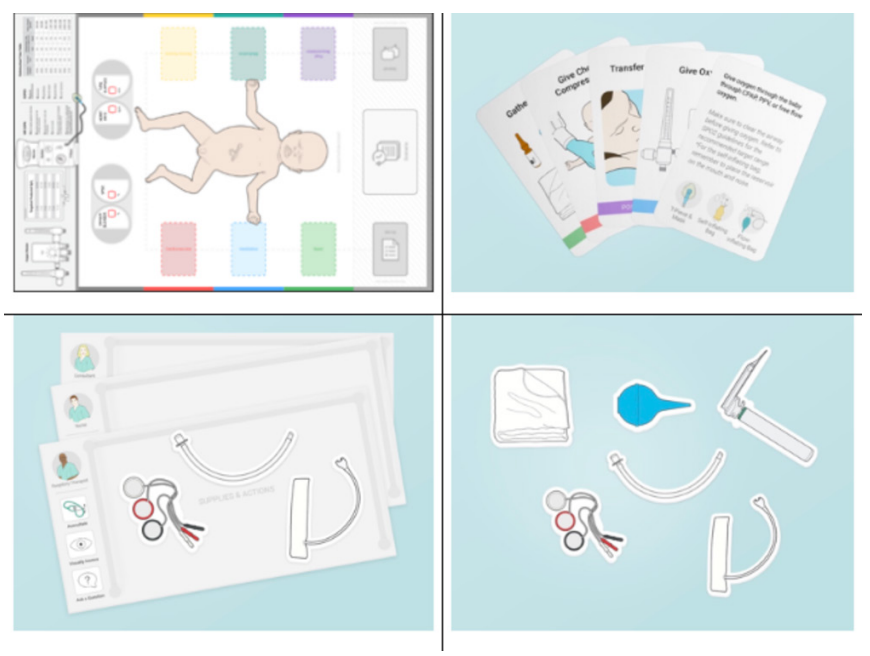

Figure 3 The RETAIN (REsuscitation TrAINing for healthcare professionals) neonatal resuscitation board game. abilities demonstrated in the game. ${ }^{37} 38$ No study has examined educational or clinical outcomes.

\section{e-Baby Nursing Neonatal Game}

To manage oxygenation problems in preterm babies, the computer game 'e-Baby' (University of São Paulo, São Paulo, Brazil) was developed to train nursing students (figure 4B). ${ }^{39} 40$ The learner is given a medical history of a preterm baby with respiratory problems, and afterwards chooses the correct clinical assessment tools and questions and answers related to the case. Fourteen nursing students played the game for a duration of 15 days and reported it was (1) 'easier to learn information', (2) 'easy to use' and (3) didactic. ${ }^{39} 40$ Moreover, 93\% of participants enjoyed the autonomy or accountability of the game. ${ }^{3940}$ A limitation of the study was the lack of any quantitative assessment of potential improvements in educational or clinical outcomes.

eHBB (Electronic Helping Babies Breathe)

eHBB (University of Washington, Seattle, Washington, USA, and Oxford University, Oxford, UK) is an integrated VR simulation training application accessible on mobile and low-cost VR devices (eg, Google cardboard). eHBB was developed to maintain training fidelity and continuous learning improvements to supplement an evidence-based, in-person global neonatal resuscitation training programme (HBB) for HCPs in low-resource settings (ie, sub-Saharan Africa). Learners manage up to three simulation scenarios to practise knowledge and skills (ie, administering PPV). ${ }^{41}$ A usability study in 24 neonatal HCPs from 
A

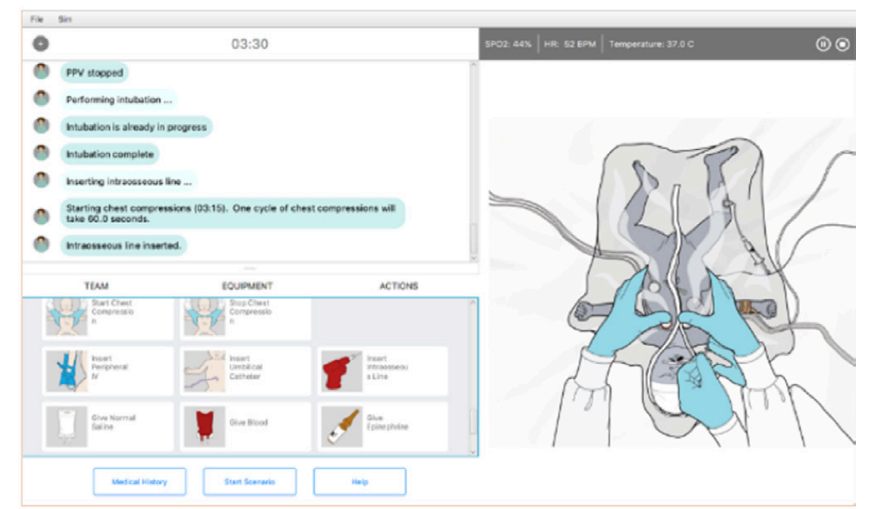

B

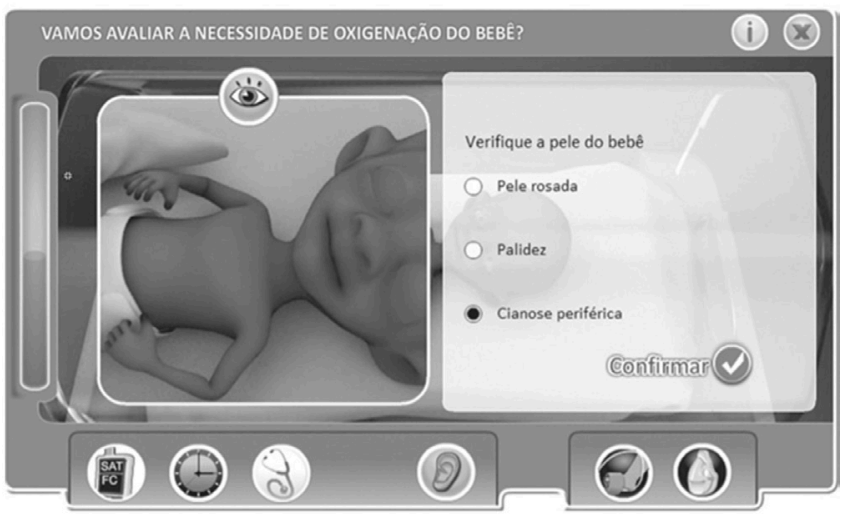

Figure 4 (A) The RETAIN (REsuscitation TrAINing for healthcare professionals) neonatal resuscitation computer game. (B) eBaby Nursing Neonatal computer game.

the National Hospital in Nigeria reported that eHBB is easy to use, educational and enables 'learning without stress'. ${ }^{41}$ There is an ongoing randomised controlled trial and cost analysis at the University of Lagos, Nigeria, and Alupe University College, Kenya.

\section{LIFE (Life-saving Instructions For Emergencies)}

LIFE (Nuffield Department of Medicine Oxford University, Oxford, UK) is a mobile and VR game developed from ETAT+ (Emergency Triage, Assessment and Treatment Plus), a face-toface medical training course based on WHO guidelines used in Africa. ${ }^{42}$ The first scenario developed for LIFE is 'Neonatal Resuscitation', where learners must find the correct equipment in a virtual rural hospital to perform time-sensitive interventions using their clinical skills. Learners also answer multiple choice questions to test their knowledge of the resuscitation protocol. ${ }^{42}$ No study has examined any educational or clinical outcomes.

\section{Compromised Neonate Program}

The Compromised Neonate Program (University of Newcastle, Callaghan, Australia) is an immersive VR tool developed to teach midwifery students' neonatal skills. ${ }^{43}$ Learners must successfully perform neonatal resuscitation in a virtual hospital within realistic time parameters. The programme has a tutorial (played with a virtual helper) and a summative assessment level (learners must perform the correct algorithm independently). ${ }^{43}$ There is an ongoing trial comparing second-year midwifery students at the University of Newcastle randomised to either (1) play the Compromised Neonate Program with the standard curriculum, compared to (2) standard curriculum alone. The learning progress of both groups will be compared to evaluate the effectiveness of the VR course as a neonatal resuscitation SBE tool. ${ }^{43}$ However, no study has examined any clinical outcomes.

\section{DISCUSSION}

To our knowledge, this is the first review to summarise the current evidence about serious games to teach neonatology. Few studies identified in this review reported knowledge improvement or knowledge retention, ${ }^{28} 29$ while other studies only observed the learners' attitudes toward the game ${ }^{303140}$ (tables 1 and 2). Design and development was variable or unreported, ${ }^{44}$ and some of the games have not been scientifically evaluated or assessed for validity, ${ }^{374} 43$ which is a major concern as both educational and clinical outcomes remain unknown (table 1). ${ }^{30} 313437404243$ All games presented in this review fit the criteria of serious games, defined as games with a primary purpose other than just entertainment (eg, with an educational or training goal), potentially improving learners' decision-making and teamwork. ${ }^{17} 4546$ All games combine psychological factors, design and technology to facilitate learning and engage users in voluntary training. ${ }^{19} 47$ Serious games (1) are widely available with minimal initial and ongoing costs for the end-user; (2) are flexible and easily accessible for HCPs with busy schedules or with those working in facilities where SBE training is not routinely offered and (3) incorporate various aspects of gamification to provide an attractive and intrinsically motiving learning experience (eg, competition, emotional design, autonomy). ${ }^{39} 48-50$

\section{Competition}

Competition has the potential to improve learning, because stressful situations improve knowledge retention and decisionmaking skills. ${ }^{5152}$ Points, badges and leaderboards are examples of visual and quantifiable representations of attained goals (ie, accumulating points after correctly answering questions) and have been associated with improved decision-making due to competition among HCPs (ie, improving the health of a simulated newborn). ${ }^{29} 303335373953$ Competition affects the learner's emotional state by inducing either a euphoric high arousal enjoyment after victory, thereby increasing motivation to continue playing ${ }^{54}$ or angry frustrated adverse emotions, which may also increase motivation to continue playing to be successful with the next scenario. ${ }^{55}$

\section{Emotional design}

Emotional components (eg, crying, heartbeat or breathing sounds) stimulate the visceral, behavioural and reflective levels of the emotional system. ${ }^{475256}$ These three levels interact to create an overall emotional experience of the game. The visceral level is responsible for the automatic primary qualities of human emotion, which are almost entirely out of our control. ${ }^{52}$ The behavioural level refers to the controlled aspects of human action by unconsciously analysing a situation to develop goaldirected strategies to improve effectiveness (eg, preventing a newborn from dying). ${ }^{52}$ The reflective level is responsible for reflection, conscious thought and learning of new concepts (eg, being accountable for the action taking in the game and their consequences). ${ }^{52}$

\section{Autonomy}

Autonomy addresses HCPs being accountable for their learning objectives, which are not always addressed during instructor-led SBE training. ${ }^{15}$ Autonomy fosters self-directed learning without 
the stress of a scheduled SBE training session. ${ }^{57}$ Indeed, serious games allow learners to train neonatal resuscitation independently at any time and place, ${ }^{58}$ to choose which topics they want to study at their pace outside a mandatory class schedule. ${ }^{33} 3943$ In addition, serious games employ self-determination theory to optimise a learner's intrinsic (ie, enjoyment and fulfilment from the activity itself) and extrinsic (ie, activity valued only by external reward and punishment) motivation to play the game to improve their knowledge. ${ }^{59}$

\section{Assessment}

Serious games can be used as formative assessments, as they allow for immediate formative feedback during play. ${ }^{28} 333637404243$ This immediate feedback allows the learner to improve their knowledge and skills in preparation for consequent scenarios or improve their performance in reality. ${ }^{60} 61$ Furthermore, serious computer games can be used as summative assessments, as they collect the learner's action sequences, evaluate their correctness and provide a performance summary at the end of each scenario. ${ }^{1343743}$ Finally, serious games can be used as preinstructional assessment tools (eg, knowledge assessment before an NRP course) to identify a learner's strengths and weaknesses.

\section{LIMITATIONS}

There are several limitations of board games including the need to coordinate time for small learner groups to meet in the case of multiplayer sessions, set-up time and available space to play the game. Similarly, limitations of video games include accessibility (eg, access to a computer, smartphone or tablet), high cost of initial development and consistent updating, immersion leading to excessive use and even game addiction, or misuse (eg, cyberbullying due to leaderboards). Furthermore, up to $60 \%$ of VR users report motion sickness and dizziness, which might limit the application of VR for SBE. ${ }^{62}$ Just as with conventional simulation, games can lead to stressful experiences for players, due to the serious content of scenarios, anxieties about performance or interpersonal dynamics between players. ${ }^{11}$

\section{CONCLUSIONS}

Serious games have the potential to improve HCPs' knowledge, skills and adherence to the resuscitation algorithm. Serious games could supplement traditional teaching and enhance access to medical education in resource-intense and resourcelimited areas. Future research should examine if serious games compared with traditional SBE or a combination of both can reduce medical errors, improve patient safety and improve clinical outcomes in newborn infants.

Contributors Conception: GMS, SKG, SDP, MC, MRGB, TJ, PvH. Literature search: GMS, SKG, SDP, MC, MRGB, TJ, PvH. Drafting of the manuscript: GMS, SKG, MC, MRGB, SDP, TJ, PvH. Critical revision of the manuscript: GMS, SKG, MC, MRGB, SDP, TJ, PvH. Final approval of the manuscript: GMS, SKG, MC, MRGB, SDP, TJ, PvH.

Funding We thank the public for donating money to our funding agencies: SKG is a recipient of the Maternal and Child Health (MatCH) Scholarship Program (supported by the University of Alberta, Stollery Children's Hospital Foundation, Women and Children's Health Research Institute and the Lois Hole Hospital for Women). GMS is a recipient of the Heart and Stroke Foundation/University of Alberta Professorship of Neonatal Resuscitation, a National New Investigator of the Heart and Stroke Foundation Canada and an Alberta New Investigator of the Heart and Stroke Foundation Alberta.

Competing interests MRGB, PvH and GMS have registered the RETAIN board game (Tech ID 2017083) and the RETAIN video game under Canadian copyright (Tech ID 2017086). MRGB and GMS are owners of RETAIN Labs Medical, Edmonton, Alberta, Canada (https://www. playretain.com), which is distributing the game.

Patient consent for publication Not required.
Provenance and peer review Not commissioned; externally peer reviewed.

Open access This is an open access article distributed in accordance with the Creative Commons Attribution Non Commercial (CC BY-NC 4.0) license, which permits others to distribute, remix, adapt, build upon this work non-commercially, and license their derivative works on different terms, provided the original work is properly cited, appropriate credit is given, any changes made indicated, and the use is non-commercial. See: http://creativecommons.org/licenses/by-nc/4.0/.

\section{ORCID iD}

Georg M Schmölzer http://orcid.org/0000-0001-9798-2415

\section{REFERENCES}

1 Cutumisu M, Brown MRG, Fray C, et al. Growth mindset moderates the effect of the neonatal resuscitation program on performance in a computer-based game training simulation. Front Pediatr 2018;6:195.

2 Starcke K, Brand M. Decision making under stress: a selective review. Neurosci Biobehav Rev 2012;36:1228-48.

3 Wemm SE, Wulfert E. Effects of acute stress on decision making. App/ Psychophysiol Biofeedback 2017:42:1-12.

$4 \mathrm{Kim}$ Y, Woo J, Woo M. Effects of stress and task difficulty on working memory and cortical networking. Percept Mot Skills 2017;124:1194-210.

5 LeBlanc VR, MacDonald RD, McArthur B, et al. Paramedic performance in calculating drug dosages following stressful scenarios in a human patient simulator. Prehospital Emergency Care 2005;9:439-44.

6 Commission TJ. Sentinel event alert: preventing infant death and injury during delivery. Jt Comm 2010 2004;30.

7 Yamada NK, Halamek LP. On the need for precise, concise communication during resuscitation: a proposed solution. J Pediatr 2015;166:184-7.

8 Rall M, Manser T, Guggenberger H, et al. [Patient safety and errors in medicine: development, prevention and analyses of incidents]. Anasthesiol Intensivmed Notfallmed Schmerzther 2001:36:321-30.

9 Hunziker S, Pagani S, Fasler K, et al. Impact of a stress coping strategy on perceived stress levels and performance during a simulated cardiopulmonary resuscitation: a randomized controlled trial. BMC Emerg Med 2013;13:8.

10 Langhan TS, Rigby IJ, Walker IW, et al. Simulation-based training in critical resuscitation procedures improves residents' competence. CJEM 2009;11:535-9.

11 Müller MP, Hänsel M, Fichtner A, et al. Excellence in performance and stress reduction during two different full scale simulator training courses: A pilot study. Resuscitation 2009;80:919-24.

12 Thomas EJ, Sexton JB, Lasky RE, et al. Teamwork and quality during neonatal care in the delivery room. J Perinatol 2006;26:163-9.

13 Niermeyer S. From the Neonatal Resuscitation Program to Helping Babies Breathe: Global impact of educational programs in neonatal resuscitation. Semin Fetal Neonatal Med 2015:20:300-8.

14 Mileder LP, Urlesberger B, Schwindt J, et al. Compliance with guidelines recommending the use of simulation for neonatal and infant resuscitation training in Austria. Klin Padiatr 2014;226:24-8.

15 Mileder LP, Urlesberger B, Szyld EG, et al. Simulation-based neonatal and infant resuscitation teaching: a systematic review of randomized controlled trials. Klin Padiatr 2014;226:259-67.

16 Matterson HH, Szyld D, Green BR, et al. Neonatal resuscitation experience curves simulation based mastery learning booster sessions and skill decay patterns among pediatric residents. J Perinat Med 2018;46:934-41.

17 Connolly TM, Boyle EA, MacArthur E, et al. A systematic literature review of empirical evidence on computer games and serious games. Comput Educ 2012;59:661-86.

$18 \mathrm{Wh} \mathrm{W}$, Hsiao HC, PI W, et al. Investigating the learning-theory foundations of gamebased learning: A meta-analysis. J Comput Assist Learn 2012;28:265-79.

19 Boyle $\mathrm{E}$, Connolly TM, Hainey T. The role of psychology in understanding the impact of computer games. Entertain Comput 2011;2:69-74.

20 Graafland M, Schraagen JM, Schijven MP. Systematic review of serious games for medical education and surgical skills training. Br J Surg 2012;99:1322-30.

21 Cowan B, Sabri H, Kapralos B, et al. A serious game for off-pump coronary artery bypass surgery procedure training. Stud Health Technol Inform 2011;163:147-9.

22 Knight JF, Carley S, Tregunna B, et al. Serious gaming technology in major incident triage training: A pragmatic controlled trial. Resuscitation 2010;81:1175-9.

23 Mohan D, Fischhoff B, Angus DC, et al. Serious games may improve physician heuristics in trauma triage. Proc Natl Acad Sci U S A 2018;115:9204-9.

24 Katz D, Zerillo J, Kim S, et al. Serious gaming for orthotopic liver transplant anesthesiology: A randomized control trial. Liver Transp/ 2017;23:430-9.

25 Weiner GM. Textbook of neonatal resuscitation (NRP). 7th edn. Elk Grove Village, Illinois: American Academy of Pediatrics, 2016.

26 Zaichkin J, McCarney L, Weiner G. Are you prepared? Neonatal Netw 2016:35:184-91.

27 Umoren R, Gray M, Chitkara R, et al. Pre-course preparation with eSim computerbased simulation improves NRP provider performance on standardized simulations. Baltimore, MD, USA: Pediatric Academic Societies, 2019. 
28 Cutumisu M, Patel SD, Brown MRG, et al. RETAIN: a board game that improves neonatal resuscitation knowledge retention. Front Pediatr 2019;7.

29 Swiderska N, Thomason E, Hart A, et al. Randomised controlled trial of the use of an educational board game in neonatology. Med Teach 2013;35:413-5.

30 Gordon DW, Brown HN. Fun and games in reviewing neonatal emergency care. Neonatal Netw 1995;14:45-9.

31 Swingler GH. An evaluation of a board game as an aid to teaching neonatal primary care. Curationis 1994;17:38-9.

32 RETAIN Labs Medical Inc. RETAIN neonatal resuscitation. 2018 https://www. playretain.com/ (Accessed 28 Nov 2018).

33 Bulitko V, Hong J, Kumaran K, et al. RETAIN: a neonatal resuscitation trainer built in an undergraduate video-game class, 2015.

34 Marshall HA. Serious gaming for neonatal resucitation skills maintainance. Int J Integr Care 2014;14.

35 NHS Education for Scotland. Neonatal resuscitation game. scottish multiprof. Matern Dev. Program. 2018 https://www.scottishmaternity.org/neonatal-resuscitation-game. htm (Accessed 12 Dec 2018).

36 Neonatal Resuscitation Game. Scottish multiprofessional maternity development programme. 2018 http://neonatalresus.org.uk/ (accessed 12 Dec 2018).

37 SingHealth. Put your game face on for the babies. 2017 www.singhealth.com.sg/ TomorrowsMed/Article/Pages/Put-your-game-face-on-for-the-babies.aspx

38 Seriously HL. these are not just games but can be used to save lives, train nurses, Singapore News \& Top Stories. 2017 https://www.straitstimes.com/singapore/ seriously-these-are-not-just-games-but-can-be-used-to-save-lives-and-train-nurses

39 Fonseca LM, Aredes ND, Fernandes AM, et al. Computer and laboratory simulation in the teaching of neonatal nursing: innovation and impact on learning. Rev Lat Am Enfermagem 2016;24:2808

40 Fonseca LM, Aredes ND, Dias DM, et al. Serious game e-Baby: nursing students' perception on learning about preterm newborn clinical assessment. Rev Bras Enferm 2015;68:9-14.

41 Umoren R, Bucher S, Purkayastha S, et al. eHBB/mHBS-DHIS2: mobile virtual reality provider training in helping babies breathe. Baltimore, MD, USA: Pediatric Academic Societies, 2019

42 Paton C, Winters N, English M, et al. LIFE: life-saving instruction for emergencies, a serious game for mobile devices and VR. In: Brown J, Kostkova P, Wood C, eds. 3rd UCL centre for behaviour change digital health conference 2017: harnessing digital technology for behaviour change. London: UCL Centre for Behaviour Change and the Institute for Digital Health, 2017.

43 Univ. Newcastle Newsroom. The University of Newcastle. A new world in sight: virtual reality to advance human health. 2017 https://www.newcastle.edu.au/newsroom/ featured-news/a-new-world-in-sight-virtual-reality-to-advance-human-health.

44 Olszewski AE, Wolbrink TA. Serious gaming in medical education. Simul Healthc J Soc Simul Healthc 2017;12:240-53.

45 Graafland M, Bemelman WA, Schijven MP. Appraisal of face and content validity of a serious game improving situational awareness in surgical training. J Laparoendosc Adv Surg Tech A 2015;25:43-9.
46 Graafland M, Bemelman WA, Schijven MP. Game-based training improves the surgeon's situational awareness in the operation room: a randomized controlled trial. Surg Endosc 2017;31:4093-101.

47 El-Beheiry M, McCreery G, Schlachta CM. A serious game skills competition increases voluntary usage and proficiency of a virtual reality laparoscopic simulator during first-year surgical residents' simulation curriculum. Surg Endosc 2017;31:1643-50

48 Rutledge C, Walsh CM, Swinger N, et al. Gamification in action: theoretical and practical considerations for medical educators. Acad Med 2018;93:1014-20.

49 Bellotti F, Berta R, De Gloria A. Designing effective serious games: opportunities and challenges for research. Int J Emerg Technol Learn 2010;5:22-35.

50 Baptista G, Oliveira T. Gamification and serious games: a literature meta-analysis and integrative model. Comput Human Behav 2019;92:306-15.

51 Oudejans RRD. Reality-based practice under pressure improves handgun shooting performance of police officers. Ergonomics 2008;51:261-73.

52 DeMaria Jr S, Bryson EO, Mooney TJ, et al. Adding emotional stressors to training in simulated cardiopulmonary arrest enhances participant performance. Med Educ 2010;44:1006-15

53 Liteplo AS, Carmody K, Fields MJ, et al. Sonogames: effect of an innovative competitive game on the education, perception, and use of point-of-care ultrasound. $J$ Ultrasound Med 2018:37:2491-6.

54 Vorderer P, Hartmann T, Klimmt C. Explaining the enjoyment of playing video games: the role of competition. ICEC' 03 Proc Second Int Conf Entertain Comput 2003:2-10.

55 Grodal T. Video games and the pleasures of control. In: Zillmann D, Vorderer P, eds. Media entertainment: the psychology of its appeal. Mahway, New Jersey: Lawrence Erlbaum Associates, 2000:197-212.

56 Fonseca LM, Dias DM, Góes FS, et al. Development of the e-Baby serious game with regard to the evaluation of oxygenation in preterm babies: contributions of the emotional design. Comput Inform Nurs 2014;32:428-36.

57 Lizotte $\mathrm{MH}$, Janvier A, Latraverse $\mathrm{V}$, et al. The impact of neonatal simulations on trainees' stress and performance: a parallel-group randomized trial. Pediatr Crit Care Med 2017;18:434-41.

58 Williams J, Jones D, Walker R. Consideration of using virtual reality for teaching neonatal resuscitation to midwifery students. Nurse Educ Pract 2018;31:126-9.

59 Young J. Using a role-play simulation game to promote systems thinking. J Contin Educ Nurs 2018;49:10-11.

60 Yardley S, Teunissen PW, Dornan T. Experiential learning: transforming theory into practice. Med Teach 2012:34:161-4.

61 Carrillo-de-la-Peña MT, Baillès E, Caseras X, et al. Formative assessment and academic achievement in pre-graduate students of health sciences. Adv Health Sci Educ Theory Pract 2009;14:61-7.

62 Munafo J, Diedrick M, Stoffregen TA. The virtual reality head-mounted display Oculus Rift induces motion sickness and is sexist in its effects. Exp Brain Res 2017;235:889-901. 